\title{
MUDANÇA LEXICAL NA DESIGNAÇÃO DE UMA BRINCADEIRA INFANTIL: PESQUISA GEOLINGUIISTICA REALIZADA EM MANAUS
}

\author{
Soraya Paiva Chain* \\ Felício Wessling Margotti*
}

Resumo: O objetivo deste texto é relatar uma pesquisa de caráter geolinguístico pluridimensional sobre variantes lexicais referentes ao lema amarelinha na comunidade de fala da cidade de Manaus. Para a realização do estudo, levamos em conta a divisão da capital amazonense em seis zonas e a composição de cada zona, considerando a área, os bairros e o número de habitantes. Em cada uma das seis zonas, foi selecionada uma escola e nela foram feitas 48 entrevistas (8 em cada escola), sendo metade dos indivíduos com idade de 6 a 10 anos e cursando do $1^{\circ}$ ao $5^{\circ}$ ano escolar, e a outra metade com idade de 11 a 14 anos e cursando do $6^{\circ}$ ao $9^{\circ}$ ano. Nas entrevistas, foi utilizada a questão 167 do Questionário Semântico Lexical do Atlas Linguístico do Brasil (ALiB) que indaga sobre o nome da brincadeira em que as crianças riscam uma figura no chão, formada por quadrados numerados, jogam uma pedrinha e vão pulando com uma perna só. De acordo com o levantamento, todos os 48 informantes deram como primeira resposta o item lexical amarelinha. $\mathrm{O}$ item macaca, que marcava a fala regional no Amazonas e em Manaus em tempos pretéritos, foi obtido como segunda resposta somente em 2,083\% das entrevistas e como forma sugerida em $12,5 \%$. O resultado evidencia forte influência exógena na fixação do léxico, ao menos em relação ao item lexical pesquisado.

Palavras-chave: Geolinguística; variação lexical; amarelinha; macaca; Manaus.

* Universidade Federal de Santa Catarina. 


\begin{abstract}
The aim of this text is to report a search of pluridimensional geolinguistic character on lexical variants related with lemma amarelinha in the speech community of the city of Manaus. For the study, we took into account the division of the capital of Amazonas in six zones and the composition of each zone, considering the area, the neighborhoods and the number of inhabitants. In each of the six zones, we selected a school and in it were done 48 interviews ( 8 in each school), being half of individuals aged 6 to 10 years and attending of the $1^{\text {st }}$ to $5^{\text {th }}$ grade, and the other half aged 11 to 14 years and attending of the $6^{\text {th }}$ to $9^{\text {th }}$ grade. In the interviews, was used the question 167 of Lexical Semantic Questionnaire of the Linguistic Atlas of Brazil (ALiB) that inquires about the name of the game in which the children scratch a figure on the ground, formed by numbered squares, throw a pebble and go jumping with only a leg. According to the survey, all the 48 individuals gave as the first answer the lexical item amarelinha. The item macaca, which marked the regional speak in Amazonas and in Manaus in past times, was obtained as second response only in $2.083 \%$ of the interviews and as form suggested in $12.5 \%$. The result shows strong exogenous influence in fixing the lexicon, at least in relation to the lexical item searched.
\end{abstract}

Keywords: Geolinguistics; lexical variation; amarelinha; macaca; Manaus.

\title{
Introdução
}

Informações obtidas pelo Atlas Linguístico do Amazonas (CRUZ, 2004) e pelo Atlas Linguístico do Brasil (BASSI E MARGOTTI, 2012, v. 1, p. 49-78) revelam que na região norte do Brasil usa-se predominantemente o item lexical macaca para se referir a uma brincadeira em que as crianças riscam uma figura no chão, formada por quadrados numerados, jogam uma pedrinha e vão pulando com uma perna só. Essa também era a forma usada pelos habitantes de Manaus em tempos pretéritos, como bem revelam os habitantes mais velhos. Atualmente, no entanto, o termo mais comum para o mesmo referente, ao menos entre os falantes jovens, é outro, fato que se pretende demonstrar por meio de uma pesquisa feita com base em princípios da sociolinguística 
variacionista (WEINREICH, LABOV E HERZOG, 2006) e da dialetologia pluridimensional (THUN E RADTKE, 1996).

Com vistas a documentar uma possível mudança lexical em Manaus, mais especificamente no campo semântico relacionado a uma brincadeira infantil, optou-se pela realização de uma pesquisa de campo, concretizada por meio de entrevistas. A amostra constitui-se de 48 jovens nascidos e residentes na referida cidade, estratificados quanto à idade, sexo, escolaridade e zona residencial, tomando como base o lema amarelinha, objeto da questão 167 do Questionário Semântico-Lexical do Atlas Linguístico do Brasil, a saber: "a brincadeira em que as crianças riscam uma figura no chão, formada por quadrados numerados, jogam uma pedrinha (mímica) e vão pulando com uma perna só". Dentre as respostas obtidas, citam-se amarelinba, macaca e macaquinba.

Conforme o contexto, considerando critérios semânticos (OLIVEIRA, 2008), sabe-se que amarelinha retrata uma brincadeira infantil ou uma cor no diminutivo. De outra parte, mesmo que se abandonem os critérios semânticos propostos por Oliveira (2008) e se adotem critérios sintáticos e morfológicos (LYONS, 1987), tem-se macaca para uma brincadeira infantil e macaca para feminino de uma espécie de animal. Ou ainda, de acordo com Lehrer apud Oliveira (2008), para a forma diminutiva macaquinha tem-se 3 palavras diferentes, uma vez que fazem parte de campos lexicais diferentes: macaquinba, "uma brincadeira infantil", pertence ao campo das brincadeiras; macaquinha, "nome de animal no diminutivo feminino", pertence ao campo dos animais; e macaquinba, "roupa feminina", pertence ao campo das indumentárias.

Além da polissemia e da homonímia, há também a sinonímia. Segundo Lyons (1987, p. 111), o significado

pode ser descritivo, expressivo e social; e muitos lexemas combinam pelo menos dois deles, senão três. Se a sinonímia for definida como identidade de significado, poderemos dizer que os lexemas são completamente sinônimos (em uma certa faixa de contextos) se, e somente se, tiverem o mesmo significado descritivo, 
expressivo e social (na faixa de contextos em questão). Poderão ser descritos como absolutamente sinônimos se, e somente se, tiverem a mesma distribuição e forem completamente sinônimos em todos os seus significados e contextos de ocorrência.

Consoante a isto, pode-se dizer que amarelinba, macaca e macaquinba são lexemas sinônimos, mas não completamente sinônimos, pois seus significados expressivo e social não são equivalentes, e muito menos absolutamente sinônimos, pois não são intercambiáveis em todos os contextos de ocorrência. Pode-se então observar que amarelinha, macaca e macaquinba são sinônimos incompletos, segundo a nomenclatura de Dubois et al. (2009):

De outra parte, diz-se que ocorre sinonímia lexical quando duas palavras têm identidade de significação relativamente ao contexto em que atuam. Trata-se de um "processo associativo que ocorre no paradigma e estabelece uma relação de conjunção entre os semas" (OLIVEIRA, 1999 apud MARGOTTI, 2003, p. 32).

O objetivo desta pesquisa é mostrar que a comunidade de fala de Manaus, influenciada tanto pela mídia - no caso em estudo, através de programas infantis produzidos principalmente no Rio de Janeiro e em São Paulo -, quanto pelo contato com imigrantes, vindos de outras regiões do país para fixar moradia nesta cidade, não usa mais o item lexical que denominava a citada brincadeira infantil nas décadas anteriores a esta. Utiliza, agora, para tal brincadeira, o mesmo item lexical que as comunidades de fala das cidades do Rio de Janeiro e São Paulo usam.

\section{As seis zonas da cidade de Manaus: localização, características e perfil dos habitantes}

Manaus é dividida pela prefeitura da cidade em seis zonas administrativas, a saber: Norte, Sul, Centro Sul, Leste, Oeste e Centro Oeste. Essas zonas se dividem em 56 bairros. 


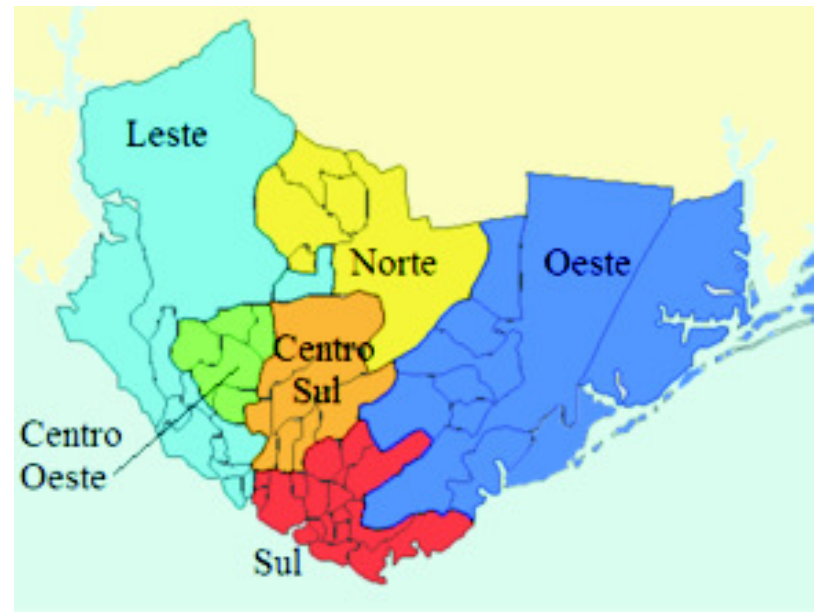

FIGURA 1: As seis zonas administrativas da cidade de Manaus ${ }^{1}$

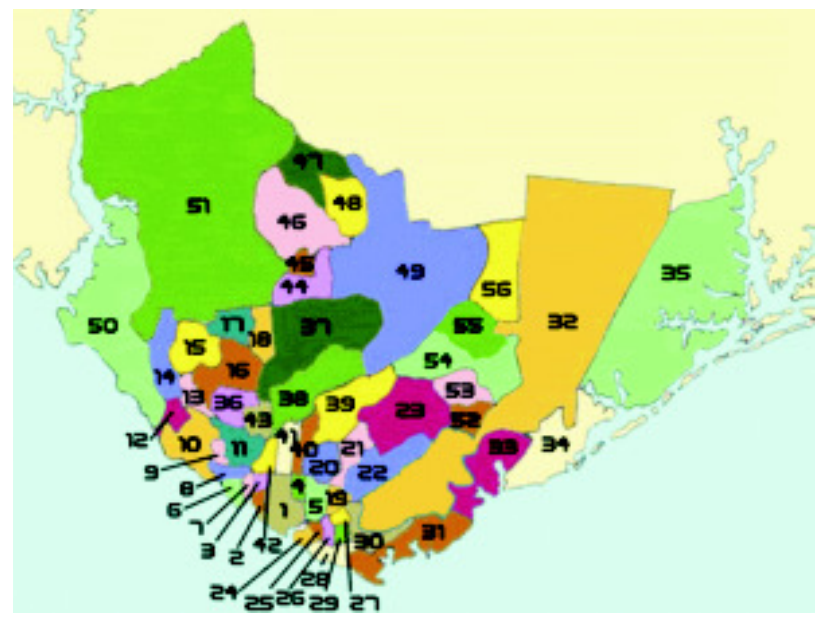

FIGURA 2: Bairros da cidade de Manaus ${ }^{2}$

${ }^{1}$ Disponível em: http://www.manausonline.com/images/mapa_bairros2.gif; acesso em 30/08/2013. Adaptado.

${ }^{2}$ Disponível em: http://i63.photobucket.com/albums/h137/joaobbb/ mapa_bairros_manaus.gif; acesso em 30/08/2013. 
QUADRO 1

As zonas de Manaus incluídas na pesquisa e os respectivos bairros

\begin{tabular}{|l|l|l|l|l|l|}
\hline \multicolumn{1}{|c|}{ Zona Norte } & \multicolumn{1}{|c|}{ Zona Sul } & \multicolumn{1}{|c|}{$\begin{array}{c}\text { Zona } \\
\text { Centro Sul }\end{array}$} & \multicolumn{1}{c|}{ Zona Leste } & \multicolumn{1}{c|}{ Zona Oeste } & \multicolumn{1}{c|}{ Zona } \\
Centro Oeste
\end{tabular}

Segundo a ARSAM (Agência Reguladora dos Serviços Públicos do Estado do Amazonas), "a cidade de Manaus, atualmente, possui em torno de 420 áreas residenciais, abrangendo conjuntos, condomínios, invasões e loteamentos" (ARSAM, 2010).

A Zona Norte de Manaus ${ }^{3}$ é a segunda maior região da cidade e, na última década, foi a que mais cresceu em termos populacionais; ocupa a maior área do município, mais de 6000 $\mathrm{km}^{2}$; tem o maior bairro da cidade, a Cidade Nova, que abriga mais de 210 mil moradores; e é constituída por seis bairros. Esta zona apresenta um dos piores índices de educação do Amazonas, mas nela localiza-se um dos melhores colégios do estado, a Escola Estadual Dulcineia Varela. Nessa região reside grande quantidade de pessoas de baixa renda que chegam de outros municípios do Amazonas ou de outras cidades do país.

\footnotetext{
${ }^{3}$ Os dados referentes às seis zonas de Manaus sintetizados a seguir foram extraídos dos respectivos verbetes da Wikipédia.
} 
A Zona Sul de Manaus é a região com o maior número de bairros, são 17. Nessa zona tem-se o Centro, bairro mais agitado da cidade, com o Teatro Amazonas, símbolo do município, e um dos mais importantes teatros brasileiros, considerado também o mais belo; há também os bairros mais antigos da cidade, Colônia Oliveira Machado, Educandos, entre outros. O Japiim é o bairro mais populoso desta zona, com uma população de aproximadamente 58.616 habitantes para uma área de 420.000 hectares. Essa zona, talvez pelo fato de alguns de seus bairros serem banhados pelo Rio Negro, é ocupada predominantemente por pessoas vindas de outros municípios do Amazonas.

A Zona Centro Sul é a região mais nobre da cidade, além de ser a que possui o maior número de prédios. Ocupa uma área pequena do município, no total não chega a $1000 \mathrm{~km}^{2} \mathrm{e}$, grande parte dela pertence ao Estado. É a zona mais urbanizada e a que apresenta os menores problemas sociais, com uma população de quase 200.000 e renda média de quase $R \$ 4.000,00$ por habitante - dados do IBGE 2008. Estão localizados nesta zona os três maiores shoppings centers de Manaus: o maior de toda a região norte do Brasil - o Manauara Shopping; o segundo maior e mais antigo da cidade - o Amazonas Shopping; e o Millenium Center, considerado um dos shoppings mais luxuosos do norte do país. Esta é uma das zonas que mais abriga pessoas mais abastadas advindas de outras cidades do Brasil.

A Zona Leste de Manaus é a maior região da cidade e forma com a zona norte a macrozona conhecida como "zona de crescimento". Pessoas menos abastadas, advindas de outros municípios do Amazonas ou de outras cidades do país fixam residência em uma destas zonas. Nesta zona, estão localizados o maior centro comercial do município e alguns dos bairros mais populosos, além de ser a zona mais populosa da cidade. A ocupação da zona leste é diversa, pois nela há bairros ricos e bairros pobres. Há, nela, dois shoppings centers, o maior hospital do estado - o Pronto Socorro João Lúcio Pereira Machado - e a maior 
maternidade da Região Norte - a Maternidade Ana Braga. É também nesta zona que está situado o Campus da UFAM, que cobre uma área de aproximadamente 600 hectares, com floresta primária, floresta secundária e áreas desmatadas com plantações.

A Zona Oeste de Manaus ocupa quase $2000 \mathrm{~km}$ do município. Os bairros dessa região são os mais próximos do Rio Negro. O maior bairro dessa zona é a Compensa que abriga mais de 70 mil moradores. A zona oeste possui uma população muito diversificada, pois nela está localizado o bairro mais luxuoso da cidade, a Ponta Negra, que, além de ser um dos cartões postais do município, é um bairro turístico, com condomínios e prédios luxuosíssimos, anfiteatro, hotel, restaurantes, estacionamento e muito mais. Este bairro é procurado por pessoas abastadas que vêm de outras cidades para fixarem residência em Manaus. Em contrapartida, vemos no bairro Tarumã o crescimento de favelas e uma infraestrutura precária, com a falta de asfalto, água e eletrificação. Fora a Ponta Negra, os outros bairros banhados pelo Rio Negro (Tarumã, Santo Agostinho, Compensa, Santo Antônio, São Raimundo e Glória) abrigam grande parte de pessoas vindas de municípios vizinhos, talvez por intermédio do rio.

A Zona Centro Oeste de Manaus é uma das regiões mais bem localizadas da cidade. Ocupa quase $1500 \mathrm{~km}^{2}$ do município. O maior bairro desta zona é o Alvorada, que abriga quase $70 \mathrm{mil}$ moradores. Há também o Bairro da Paz e o Dom Pedro I, que, dentre outros, são bairros nobres. Este último possui uma das maiores praças de alimentação da cidade e um dos maiores e melhores hospitais da região norte, o Instituto de Medicina Tropical de Manaus, conhecido como Hospital Tropical. Essa zona possui apenas 5 bairros de classes média e alta, vários conjuntos, avenidas de grande fluxo e comércio bem desenvolvido. Quase não há favelas. Igualmente à zona Centro Sul, abriga pessoas com mais recursos, vindas de outras cidades do país, principalmente das regiões sudeste e sul. 
Vê-se então que Manaus é uma cidade plural, cheia de riquezas e de pobrezas, mas é uma cidade maravilhosa, a capital do estado do Amazonas, que fica no centro da maior floresta tropical do mundo e possui uma área de $11401 \mathrm{~km}^{2}$, sendo 229504 $\mathrm{km}^{2}$ de perímetro urbano.

\section{Dados do ALAM e do ALiB}

O Atlas Linguístico do Amazonas - ALAM (CRUZ, 2004) contempla a coleta de dados em 9 municípios do Amazonas (Barcelos, Tefé, Benjamin Constant, Eirunepé, Lábrea, Humaitá, Manacapuru, Itacoatiara e Parintins) por meio de entrevistas feitas com 6 informantes de cada município, sendo 3 do sexo feminino e 3 do sexo masculino. Para cada uma das três faixas etárias consideradas (18 a 35, 36 a 55 e acima de 56 anos), foi entrevistado um informante de cada sexo.

As respostas à pergunta 78 do Questionário SemânticoLexical do ALAM - "a brincadeira em que as crianças riscam uma figura no chão, formada por quadradinhos numerados, jogam uma pedrinha (mímica) e vão pulando com uma perna só" - foram apresentadas na carta semântico-lexical de número 8. Dentre as 54 entrevistas, 38 informantes não souberam nominar a brincadeira, 15 a nominaram com o item lexical macaca e 1 informante a nominou com o item lexical saci. Ou seja, nenhum dos entrevistados usou o item lexical amarelinha como resposta.

Dados obtidos pelo Atlas Linguístico do Brasil (ALiB) revelam que nas capitais dos estados da região norte do Brasil (Macapá, Boa Vista, Manaus, Belém, Rio Branco, Porto Velho), em 48 entrevistas, com informantes estratificados em mais velhos e mais jovens, homens e mulheres, escolaridade baixa e escolaridade alta, $o$ item lexical macaca foi empregado por $50 \%$ dos informantes como resposta à pergunta cujo lema é a brincadeira infantil amarelinha . Em segundo lugar, registrou-se a palavra amarelinha com 31\% das ocorrências. $19 \%$ dos informantes não souberam responder. 


\section{Procedimentos metodológicos}

Para a realização deste trabalho, utilizou-se a metodologia preconizada pela geografia linguística que, de acordo com Coseriu (1982) apud Brandão (1991, p. 11) é:

o método dialetológico e comparativo (...) que pressupõe o registro (...) de formas linguísticas (fônicas, lexicais ou gramaticais) comprovadas mediante pesquisa direta e unitária numa rede de pontos de determinado território, ou que, pelo menos, tem em conta a distribuição das formas no espaço geográfico correspondente à língua (...).

Os dados aqui apresentados foram coletados em entrevistas feitas com 48 informantes, nascidos em Manaus, distribuídos pelas seis zonas da cidade. Foram entrevistados 8 informantes de cada zona, sendo 4 do sexo masculino e 4 do sexo feminino. Metade dos 48 informantes está na faixa etária de 6 a 10 anos de idade e são do $1^{\circ}$ ao $5^{\circ}$ ano escolar. A outra metade está na faixa etária de 11 a 14 anos e são do $6^{\circ}$ ao $9^{\circ}$ ano.

As entrevistas foram realizadas em Escolas Estaduais, sendo uma escola de cada zona da cidade:

1. Zona Norte - Escola Estadual Júlio César de Moraes Passos, no bairro Cidade Nova. (bairro de número 49 da figura 2);

2. Zona Sul - Escola Estadual Balbina Mestrinho, no bairro Cachoeirinha (bairro de número 5 da figura 2);

3. Zona Centro Sul - Escola Estadual Anderson de Menezes, no bairro Parque 10 (bairro de número 38 da figura 2);

4. Zona Leste - Escola Estadual Rilton Leal Filho, no bairro Armando Mendes (bairro de número 52 da figura 2).

5. Zona Oeste - Escola Estadual Antônio Encarnação Filho, no bairro Lírio do Vale (bairro de número 14 da figura 2);

6. Zona Centro Oeste - Escola Estadual Francisca Botinelly Cunha e Silva, no bairro Dom Pedro II (bairro de número 36 da figura 2); 
Com o objetivo de mostrar que a comunidade de fala de Manaus já não utiliza mais o item lexical macaca, usado nas décadas anteriores a esta, foram feitas as 48 entrevistas, com a pergunta inicial "qual o nome da brincadeira em que as crianças riscam uma figura no chão, formada por quadradinhos numerados, jogam uma pedrinha e vão pulando, ora com uma perna só, ora com duas pernas", baseada na questão 167 do Questionário Semântico Lexical do Atlas Linguístico do Brasil (ALiB).

O objetivo da primeira pergunta foi obter uma resposta espontânea, a partir da qual foi feita uma segunda pergunta: "conhece outro nome para (mencionar a resposta à primeira pergunta)", com a pretensão de saber se o falante conhecia outras palavras para se referir à mesma brincadeira infantil.

No caso de não se ter obtido nenhuma resposta às duas primeiras perguntas, foram sugeridas sete variantes lexicais, precedidas da pergunta: "Você conhece / sabe o que significa ..." (seguem as formas sugeridas, uma a uma). Essas sete variantes lexicais, com a indicação de possíveis áreas de ocorrência, foram obtidas nas entrevistas do ALiB nas capitais dos estados (BASSI E MARGOTTI, 2012) estão relacionadas no quadro 2.

\section{QUADRO 2}

Formas sugeridas aos informantes de Manaus que não responderam a pergunta à brincadeira infantil, cujo lema é amarelinha

\begin{tabular}{|l|l|l|l|l|l|}
\hline Formas sugeridas & $\mathbf{1}^{\mathbf{a}}$ resposta & $\mathbf{2}^{\mathbf{a}}$ resposta & $3^{\mathbf{a}}$ resposta & Conhece & Não conhece \\
\hline 1. macaca (Manaus, Belém) & & & & & \\
\hline 2. amarelinha (RJ, SP, PR, GO, MG) & & & & & \\
\hline 3. sapata (Front. do RS com Argentina) & & & & & \\
\hline 4. (a)cademia (Recife) & & & & & \\
\hline 5. avião (Maceió) & & & & & \\
\hline 6.pula macaco (Salvador) & & & & & \\
\hline 7. macaquinho (Salvador) & & & & & \\
\hline
\end{tabular}

As respostas obtidas foram analisadas e descritas com base nas variáveis extralinguísticas sexo e faixa etária/escolaridade dos informantes. 


\section{Análise e discussão sobre a mudança lexical}

Foram obtidos, com o levantamento das denominações dadas pelos 48 informantes das seis zonas de Manaus, 100\% das respostas válidas, registrando três diferentes denominações para a brincadeira infantil que foi pesquisada.

$\mathrm{O}$ item lexical amarelinha aparece como primeira resposta em 100\% das entrevistas; macaca e macaquinha aparecem como segunda resposta, cada uma por entrevistados distintos; e, dentre as formas sugeridas, seis dos entrevistados disseram que conhecem o item lexical macaca como também denominador da mesma brincadeira infantil, nomeada primeiramente por eles como amarelinba.

Em todas as seis zonas de Manaus, o item lexical amarelinba apresentou-se de forma unânime na primeira resposta. Como segunda resposta, há um registro de macaca na Zona Norte e um registro de macaquinha na Zona Sul. Como forma sugerida, macaca é registrada três vezes na Zona Leste, duas vezes na Zona Oeste e uma vez na Zona Sul.

Foram descartadas as informações obtidas em relação a algumas formas sugeridas por se apresentarem inadequadas a esta pesquisa. Em todas as entrevistas, depois de obter-se a primeira resposta, a resposta espontânea, e inquirir uma segunda resposta, a resposta adicional, sugeriram-se outros itens lexicais utilizados para denominar a mesma brincadeira infantil, em outras cidades/ estados brasileiros, tais como: macaca (Manaus, Belém), amarelinba (RJ, SP, PR, GO, MG), sapata (fronteira do RS com Argentina), (a)cademia (Recife), avião (Maceió) e pula macaco (Salvador).

Como exemplo de respostas descartadas tem-se: macaca - "animal"; academia - "local de fazer atividades físicas"; avião "transporte aéreo". 


\section{QUADRO 3}

Distribuição diatópica dos itens lexicais, de acordo com as zonas manauaras

\begin{tabular}{|l|l|l|l|c|}
\hline \multicolumn{1}{|c|}{ Conceito } & Zonas & \multicolumn{3}{c|}{ Itens lexicais obtidos } \\
\hline \multirow{4}{*}{$\begin{array}{l}\text { Brincadeira infantil, disposta no chão } \\
\text { através de quadradinhos enumerados, } \\
\text { que a criança pula, ora com uma } \\
\text { perna só, ora com duas pernas. }\end{array}$} & Sorte & amarelinha & macaca & \\
\cline { 2 - 5 } & Sul & amarelinha & macaquinha & macaca \\
\cline { 2 - 5 } & Leste & amarelinha & & \\
\cline { 2 - 5 } & Oeste & amarelinha & & macaca \\
\hline & Centro Oeste & amarelinha & & macaca \\
\hline
\end{tabular}

O quadro 3 mostra a hegemonia do item lexical amarelinha em todas as zonas manauaras e apresenta dois outros itens lexicais (macaca e macaquinha) que ainda são lembrados espontaneamente como segunda resposta. Dentre as sete respostas sugeridas, apenas o item macaca foi reconhecido por seis entrevistados.

A seguir, os resultados da pesquisa serão correlacionados com as variáveis extralinguísticas sexo e faixa etária/escolaridade.

Os gráficos 1 e 2 apresentam as respostas espontâneas, as segundas respostas e as formas sugeridas reconhecidas, considerando a variável extralinguística sexo, nas seis zonas manauaras.

Pode-se observar que ainda há registro do item lexical macaca na fala dos manauaras. Essa resistência ocorre mais em falantes do sexo feminino, conforme gráficos 1 e 2 , representados abaixo.

Observa-se também um registro de macaquinba (talvez forma carinhosa de denominar a brincadeira macaca no diminutivo) em apenas $12,5 \%$ dos entrevistados do sexo feminino, como segunda resposta. 

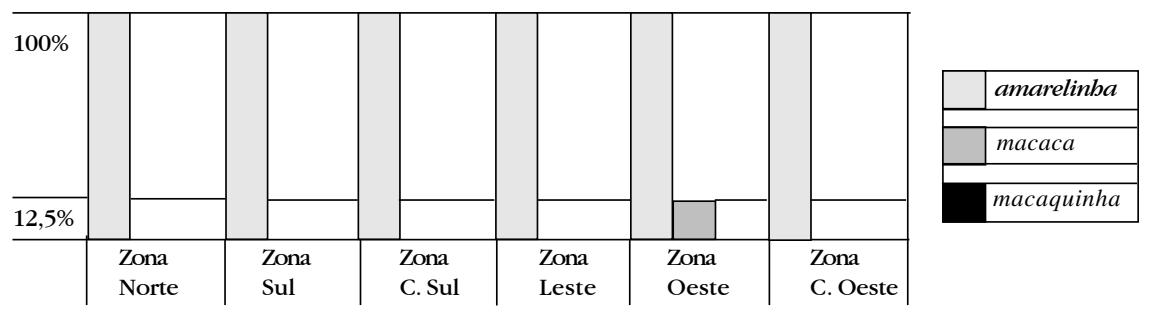

GRÁFICO 1: Distribuição diatópica dos itens lexicais que designam a brincadeira infantil analisada, considerando a variável extralinguística sexo masculino nas seis zonas de Manaus

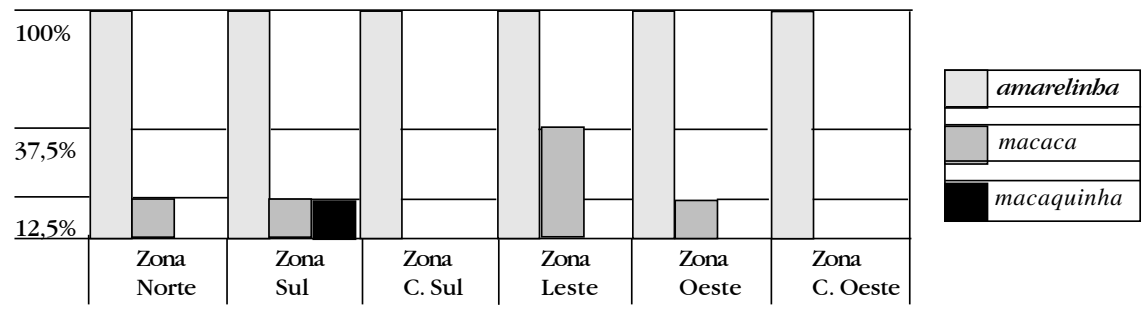

GRÁFICO 2: Distribuição diatópica dos itens lexicais que designam a brincadeira infantil analisada, considerando a variável extralinguística sexo feminino nas seis zonas de Manaus

Os gráficos 3 e 4 apresentam resposta espontânea, segunda resposta e forma sugerida, considerando as variáveis extralinguísticas faixa etária/escolaridade, nas seis zonas manauaras.

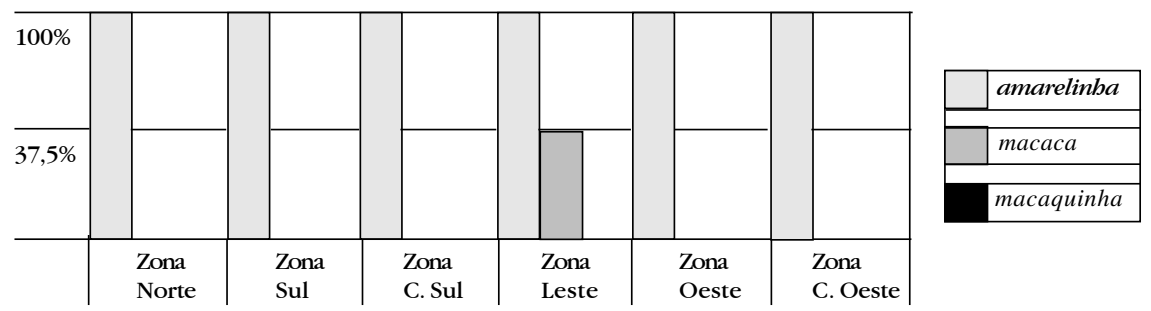

GRÁFICO 3: Distribuição diatópica dos itens lexicais que designam a brincadeira infantil analisada, considerando as variáveis extralinguísticas faixa etária (6 a 10 anos) e escolaridade $\left(1^{\circ}\right.$ ao $5^{\circ}$ ano) nas seis zonas de Manaus 


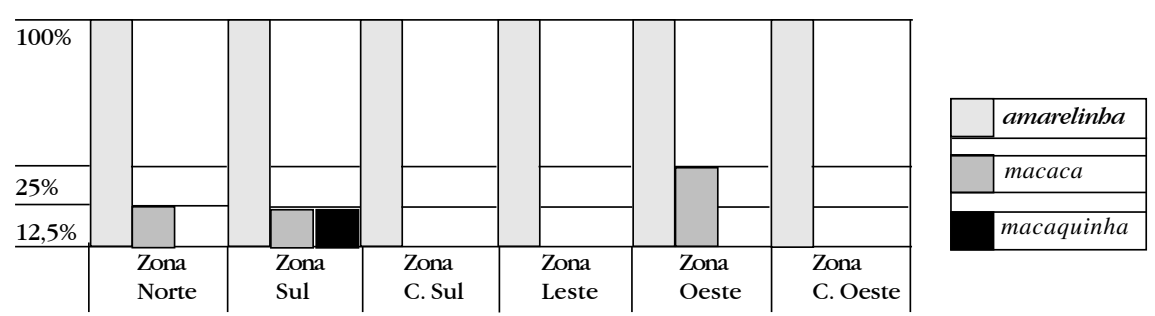

GRÁFICO 4: Distribuição diatópica dos itens lexicais que designam a brincadeira infantil analisada, considerando as variáveis extralinguísticas faixa etária (11 a 14 anos) e escolaridade $\left(6^{\circ}\right.$ ao $9^{\circ}$ ano $)$ nas seis zonas de Manaus

O que se observa em relação à faixa etária/escolaridade é que, na faixa etária mais jovem, alguns entrevistados da Zona Leste, após ouvirem as formas sugeridas, informam que conhecem a denominação macaca.

$\mathrm{Na}$ faixa etária mais velha, observa-se que apenas $12,5 \%$ das respostas obtidas em duas zonas (Norte e Sul) apontam macaca e macaquinha, respectivamente, como segunda resposta e, como forma sugerida, macaca aparece com $25 \%$ na Zona Oeste e com 12,5\% na Zona Sul.

Percebe-se, com isso, que os falantes mais velhos conhecem mais o item lexical macaca, como denominador da brincadeira analisada do que os mais jovens e, na maioria das vezes, mesmo os mais velhos só o reconhecem quando essa palavra é sugerida.

O que se percebe no gráfico 5, apresentado abaixo, é que o item lexical amarelinha, que é, nos estados do RJ, SP, PR, GO e MG, além de outros estados, o denominador da brincadeira infantil analisada neste trabalho, já é também o denominador absoluto dessa mesma brincadeira em Manaus, pois é a primeira resposta dada por $100 \%$ dos entrevistados de todas as zonas da cidade. 


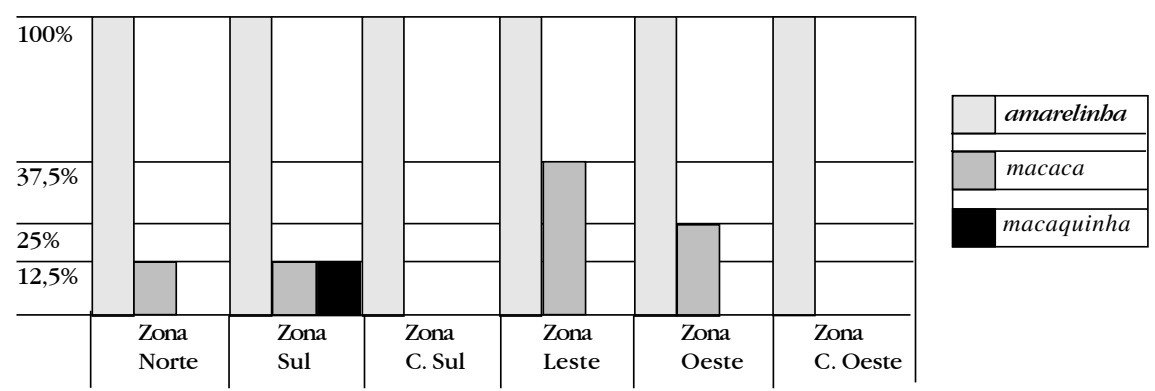

GRÁFICO 5: Distribuição diatópica dos itens lexicais que designam a brincadeira infantil analisada de $100 \%$ das entrevistas nas seis zonas de Manaus

Já o item lexical macaca, que era, em Manaus, o denominador dessa brincadeira infantil nas décadas anteriores a esta e, segundo o ALAM e o ALiB, é o denominador predominante da brincadeira em outros municípios amazonenses e mesmo na região, aparece como segunda resposta, somente em uma zona (Norte), mesmo assim em apenas 12,5\% das respostas desta zona. Na Zona Sul, obteve-se o item lexical macaquinba em 12,5\% das respostas. Entende-se que macaquinba (macaca no diminutivo) seja, no caso, uma forma carinhosa de denominar a brincadeira.

Talvez a incidência do denominador macaca/macaquinba ocorra nas Zonas Norte e Sul pelo fato de os bairros dessas zonas situarem-se próximos ao Rio Negro e, como tal, serem habitados por pessoas vindas de outros municípios do estado. A Zona Norte, além disso, é formada por pessoas de baixa renda, vindas dos municípios vizinhos e de outras cidades do país, que vieram fixar moradia em Manaus.

O denominador macaca também é obtido em $37,5 \%$ das entrevistas da Zona Leste, em 25\% da Zona Oeste e em 12,5\% da Zona Sul, como forma sugerida.

A Zona Leste é, como se viu, a maior região da cidade, além de ser a mais populosa e abrigar os bairros mais populosos. É também uma das zonas que mais abriga pessoas vindas de outros municípios do Amazonas. Talvez seja por isso que essa zona 
apresenta a maior incidência de reconhecimento do item lexical macaca, como forma sugerida. Já a Zona Oeste, que apresenta a segunda maior incidência de reconhecimento do item lexical macaca, como forma sugerida, é a região que agrega os bairros mais próximos ao Rio Negro e, possivelmente, por intermédio do rio, abriga grande parte de pessoas vindas dos municípios vizinhos. É também a região que possui o bairro mais luxuoso da cidade, a Ponta Negra, e, neste, residem pessoas abastadas, vindas de outras regiões do país, como sul e sudeste.

Nesse caso, o que se tem é que a forma macaca é reintroduzida na fala manaura pelos que vieram de fora, reforçando a ideia de que as formas linguísticas, assim como as línguas, migram juntamente com aqueles que as usam. No novo meio, havendo formas equivalentes já estabelecidas e com mais prestígio, a tendência é que os elementos vindos de fora desapareçam.

A denominação macaca, como forma sugerida, também aparece, mas com menor incidência, na Zona Sul de Manaus.

As Zonas Centro Sul e Centro Oeste são, respectivamente, a região mais nobre e a região mais bem localizada da cidade. São zonas que abrigam pessoas mais abastadas, em sua maioria, vindas principalmente das regióes sul e sudeste do país. Pode ser por conta disso que não foi registrada nenhuma ocorrência de outro item lexical para a brincadeira analisada, fora o item amarelinha, obtido unicamente como primeira resposta nestas duas zonas.

\section{Considerações finais}

Através desta pesquisa de caráter geolinguístico pluridimensional, pôde-se observar que o item lexical macaca, com o qual se denomina uma brincadeira infantil em diferentes áreas da região norte do Brasil (CRUZ, 2004; BASSI E MARGOTTI, 2012), foi substituído na capital amazonense, pelo item lexical amarelinha. Essa variante lexical inovadora na fala dos habitantes da cidade de Manaus tem ampla difusão no português do Brasil, 
sendo atestada em todas as capitais dos estados pelo Atlas Linguístico do Brasil (BASSI E MARGOTTI, 2012), exceto em Aracaju (SE), onde a forma macacão foi categórica. Os informantes mais velhos, mesmo conhecendo a variante conservadora macaca, optam pelo uso da variante trazida de fora; entre os mais jovens, na idade de 6 a 14 anos, que representem parte da amostra da presente pesquisa, prevalece o uso da forma amarelinha.

Pela análise dos dados coletados nas entrevistas e pelas informações obtidas sobre as seis zonas de Manaus, pode-se concluir que o item amarelinba substituiu o item macaca na capital amazonense. Essa substituição lexical, certamente, devese à influência da televisão na divisão de formas de prestígio, especialmente, nesse caso, por meio de programas infantis produzidos no Rio de Janeiro e em São Paulo, bem como à migração de pessoas que vieram de outras regiões do País para fixar moradia em Manaus.

Os resultados da pesquisa servem, de um lado, para confirmar o princípio de que a língua falada está sempre sujeita a diferentes possibilidades de variação lexical, além da variação em diferentes níveis da gramática. De outro, revelam que, no português falado em Manaus, existem ao menos duas variantes lexicais para designar a brincadeira em que as crianças riscam uma figura no chão, formada por quadrados numerados, jogam uma pedrinha e vão pulando com uma perna só: macaca (forma conservadora) e amarelinha (forma inovadora). Essa conclusão só foi possível porque estudos realizados anteriormente, na capital amazonense e em localidade do interior do estado, de acordo com dados fornecidos pelo Atlas Linguístico do Amazonas (CRUZ, 2004) e pelo Atlas Linguístico do Brasil (BASSI E MARGOTTI, 2012), com informantes mais velhos, revelaram o uso predominante do item macaca; em diferentes zonas de Manaus, ao contrário, com base em dados obtidos por meio de questionário aplicado a informantes jovens com vistas a subsidiar o presente estudo, a primeira e praticamente a única resposta foi amarelinba. 


\section{Referências}

ARSAM [Agência Reguladora dos Serviços Públicos do Estado do Amazonas]. Divisão administrativa da cidade de Manaus. Disponível em: < http://www.arsam.am.gov.br/novo/?q=node/163> . Acesso em: 29 set. 2010.

BASSI A.; MARGOTTI, F. W. Variantes lexicais para a brincadeira infantil amarelinha. In: ALTINO, F. C. (Org.). Múltiplos olbares sobre a diversidade linguística: uma homenagem à Vanderci Andrade Aguilera. Londrina: Madiograf, 2012. V. 1, p. 49-78.

BRANDÃO, S. F. A geografia linguística no Brasil. São Paulo: Ática, 1991. COMITÊ NACIONAL DO PROJETO ALIB. Atlas linguístico do Brasil: questionários. Londrina: Ed. da UEL, 2001.

CRUZ, M. L. de C. Atlas linguístico do Amazonas. 2004. Tese (Doutorado) - Universidade Federal do Rio de Janeiro. $2 \mathrm{v}$.

DUBOIS, J. et al. Dicionário de linguística. 11. ed. São Paulo: Cultrix, 2009.

LYONS, J. Linguagem e linguística: uma introdução. Rio de Janeiro: LTC, 1987.

MARGOTTI, F. W. Sinonímia e paráfrase: algumas considerações a partir de dados do Atlas Linguístico-Etnográfico da Região Sul - ALERS. Linguagem em (Dis)curso, Tubarão, v. 3, n. 2, p. 27-46, jan./jun. 2003.

OLIVEIRA, L. A. Manual de semântica. Petrópolis: Vozes, 20008.

WIKIPÉDIA. Zona Centro Oeste (Manaus). Disponível em: <http:// pt.wikipedia.org/wiki/Zona_Centro-Oeste_(Manaus) > . Acesso em: 27 set. 2010.

WIKIPÉDIA. Zona Centro Sul (Manaus). Disponível em: $<$ http:// pt.wikipedia.org/wiki/Zona_Centro-Sul_(Manaus) $>$. Acesso em: 27 set. 2010.

WIKIPÉDIA. Zona Leste (Manaus). Disponível em: < http://pt.wikipedia. org/wiki/Zona_Leste_(Manaus) $>$. Acesso em: 27 set. 2010.

WIKIPÉDIA. Zona Norte (Manaus). Disponível em: <http://pt.wikipedia. org/wiki/Zona_Norte_(Manaus)>. Acesso em: 27 set. 2010. 
WIKIPÉDIA. Zona Oeste (Manaus). Disponível em: <http://pt.wikipedia. org/wiki/Zona_Oeste_(Manaus)>. Acesso em: 27 set. 2010.

WIKIPÉDIA. Zona Sul (Manaus). Disponível em: < http://pt.wikipedia. org/wiki/Zona_Sul_(Manaus)>. Acesso em: 27 set. 2010.

THUN, H.; RADTKE, E. Nuevos caminos de la geolinguística românica: un balance. In: RADTKE, E.; THUN, H. (Hrsg). Neue Wege der romanischen Geolinguistik. Akten des Symposiums zur empirischen Dialektologie (Heidelberg/Mainz 21-24.10.1991). Kiel: Westensee, 1996. p. 25-49.

WEINREICH, U; LABOV, W.; HERZOG, M. Fundamentos empíricos para uma teoria da mudança linguística. 2. ed. São Paulo: Parábola, 2006.

Recebido para publicação em 30 de agosto de 2012 Aprovado em 13 de novembro de 2012 